\title{
¿RECONOCIMIENTO JURÍDICO DE LA DIVERSIDAD CULTURAL SIN EJERCICIO DE DERECHOS?
}

\author{
Elisa Cruz Rueda \\ elisacruzrueda@hotmail.com \\ Universidad Autónoma de Chiapas \\ Licenciatura en Gestión y Autodesarrollo Indígena \\ Ma. Eugenia Santana E. \\ maru.santana@gmail.com \\ Universidad Autónoma de Chiapas
}

\section{RESUMEN}

En este trabajo se presenta una revisión de cómo ha sido el reconocimiento jurídico a nivel nacional e internacional de los derechos indígenas y de sus pueblos, sus implicaciones legales y fácticas. De esta revisión se deriva el análisis de cómo se ha dado la construcción jurídico-antropológica de los conceptos de pluriculturalidad y multiculturalismo, y de lo que falta por hacer para llegar a un reconocimiento efectivo de la diversidad cultural que siente las bases de un verdadero reconocimiento y ejercicio de derechos. En este contexto, se plantea que el peritaje antropológico puede ser una herramienta que ayude al diseño de políticas públicas en y para la diversidad.

Palabras clave: pluriculturalidad, multiculturalismo, derechos indígenas, peritaje antropológico. 


\title{
LEGAL RECOGNITION OF CULTURAL DIVERSITY WITHOUT THE EXERCISE OF RIGHTS?
}

\begin{abstract}
This article presents a review of how the rights of indigenous people and their communities have been legally recognized at a national and international level, as well as the legal and factual implications this has. From this review, an analysis is derived of how the juridicalanthropological construction of the concepts of pluriculturality and multiculturalism took place. It also shows what still needs to be done to attain an effective recognition of cultural diversity that can lay the foundations of an actual recognition and exercise of rights. Within this context, anthropological investigation may be a tool to help formulate public policies within and favoring diversity.
\end{abstract}

Key words: pluriculturality, multiculturalism, indigenous rights, anthropological investigation. 


\section{INTRODUCCIÓN}

Se parte de que el peritaje antropológico es una herramienta para el diseño de políticas públicas en y para la diversidad. Entendemos como política pública toda acción o inacción gubernamental dirigida a atender determinada situación o problemática social en el marco de un plan estratégico de Estado (política de Estado). Las políticas públicas se concretizan en programas dirigidos a distintos sectores en distintos ámbitos: económico, seguridad social, cultural. Esas acciones e inacciones gubernamentales solo pueden darse apegadas a un marco jurídico, por el principio de seguridad jurídica: «para las autoridades lo que no está expresamente facultado o permitido, está prohibido», principio jurídico que es la base del Estado de derecho, ya que limita la acción gubernamental en aras del respeto a los individuos y ciudadanos.

Dado que el Estado mexicano ha firmado y ratificado una serie de instrumentos internacionales en materia de derechos humanos, está comprometido a cumplirlos a través de la modificación del marco jurídico nacional y de las políticas públicas y los programas de gobierno.

En este orden de ideas, uno de los compromisos del Estado mexicano frente al concierto de las naciones es el respeto en general a la diversidad y a la diversidad cultural, y concretamente a los derechos de los pueblos indígenas. De aquí surge el planteamiento central de este trabajo, en el que subrayamos la importancia del peritaje antropológico para el diseño de política pública y no sola para dirimir conflictos cuando se presentan a nivel jurisdiccional o administrativo.

Es decir, con el peritaje antropológico el gobierno, a través de sus funcionarios públicos, se puede allegar datos emitidos por expertos en la cultura de los «otros», llamados antropólogos, que le permitan tomar decisiones y diseñar políticas, con el fin de alcanzar dos propósitos: primero, cumplir con el marco jurídico nacional e internacional en la 
materia y, en segundo lugar, atendiendo desde un enfoque de reconocimiento y respeto étnico-cultural, determinadas necesidades o problemáticas de esta parte de la sociedad, por ejemplo, en ámbitos como la procuración y administración de justicia dirigida a los indígenas y sus pueblos.

Para explicar el planteamiento anterior abordamos el marco jurídico que determina la acción e inacción del gobierno respecto de los pueblos indígenas; posteriormente exponemos, dentro de ese marco jurídico, la normativa del peritaje antropológico para terminar con algunos ejemplos de ese tipo de peritajes tal como se realizan en la actualidad (cf. Colegio de Etnólogos y Antropólogos Sociales 2012).

\section{LOS DERECHOS HUMANOS EN EL MARCO JURÍDICO MEXICANO}

En el concierto de las naciones, por lo que toca al reconocimiento de derechos humanos en general y de derechos de los pueblos indígenas en particular, que integran el Sistema Internacional de Derechos Humanos, el Estado mexicano ha cumplido medianamente sus compromisos. Esto es evidente cuando en la actualidad los indígenas y sus pueblos reclaman el respeto a sus territorios afectados por proyectos de extracción y de infraestructura (Cruz 2011, 2013; Red Mexicana de Afectados por la Minería 2013), fundamentándose en la exigencia del cumplimiento del Convenio 169 de la Organización Internacional del Trabajo (OIT), la Declaración Universal de Derechos Humanos y, más

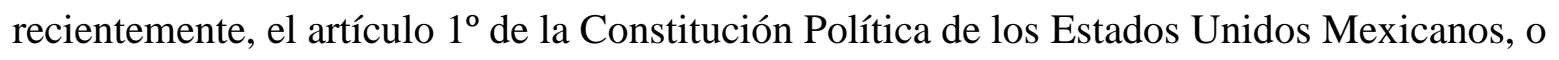
Pacto Federal, que obliga a las autoridades a cumplir con los tratados internacionales en materia de derechos humanos. Por su parte, en la Constitución del Estado de Chiapas (artículos 30, 42 y 62) se establecen directrices para ajustar la política pública y las acciones de gobierno a los llamados Objetivos del Milenio de Naciones Unidas, tal como en su momento se publicitó por los medios oficiales de gobierno estatal como la elevación de los objetivos del milenio «a rango constitucional» (cf. Gobierno del Estado de Chiapas 2012). 
Aunque existe, entonces, un marco normativo nacional e internacional en que se reconocen jurídicamente los derechos de los indígenas y sus pueblos, falta la ejecución de esas normas para hacerlos plenamente efectivos.

Partimos de que no es suficiente el marco jurídico de reconocimiento de derechos a la diversidad cultural, que se puede entender como pluralismo cultural y que se expresa en lo que se ha dado en llamar multiculturalismo -concepto que más adelante se aborda-. No es suficiente, porque finalmente esas normas de reconocimiento de derechos de los indígenas y sus pueblos se pretenden aplicar en un contexto que no ha cambiado -y como tal, es contrario a esas normas-. Es decir, en la base de la relación entre el Estado y la sociedad mexicana con los pueblos indígenas sigue la apuesta de que los indígenas dejen de ser indígenas y se asimilen a los modelos de ser y vivir (de consumismo y desarrollo) de la sociedad nacional. Así, el «deber ser» (lo que la norma señala) nos impone el reto de transitar a una realidad distinta de la que vivimos actualmente, en la que Estado, gobiernos y sociedad cambiemos mentalidades y conductas para que realmente, al relacionarnos con los «otros», por ejemplo, los indígenas, reconociendo su dignidad como personas y representantes de culturas distintas, y que entonces podamos hablar de interculturalidad.

En este trabajo, expondremos cómo se ha dado el reconocimiento a la diversidad cultural, su marco jurídico, los derechos derivados de tal reconocimiento, los conceptos asociados, las implicaciones en cuanto a su ejercicio y cómo el peritaje antropológico sustentado en ese marco jurídico puede ser una herramienta en el diseño de políticas públicas de y para la diversidad.

\section{RECONOCIMIENTO JURÍDICO DEL MULTICULTURALISMO EN MÉXICO}

En otro trabajo (Ortelli et al. 2012) se señaló que el reconocimiento jurídico constitucional del pluralismo cultural se da en México por primera vez en 1992, con el artículo $4^{\circ}$ y el 
segundo párrafo de la fracción VII del artículo 27, ambos de la Constitución Federal, aunque la educación indígena bilingüe ya se había introducido mucho tiempo atrás (Pérez 2009).

Posteriormente, en 2001, y después de que en 1996 se firmaran los Acuerdos de San Andrés, se promueve por parte del gobierno federal la reforma constitucional -en un contexto de un gran debate y cuestionamiento de la iniciativa del entonces presidente Fox- ${ }^{1}$ en la que de nueva cuenta se hace el reconocimiento de la pluriculturalidad de la nación mexicana, al quedar asentado en el artículo $2^{\circ}$ constitucional, que dice a la letra: «la nación tiene una composición pluricultural sustentada originalmente en sus pueblos indígenas».

Tal norma jurídica establece a la vez oposición y complementariedad. Por un lado señala que la pluriculturalidad está representada por los pueblos indígenas frente a la nación indígena y no indígena, y por otro lado, y en consecuencia, esta nación está integrada por dos partes o polos distintos y a la vez complementarios -esto según la norma jurídica-, aunque de facto o de hecho la realidad muestra un sinnúmero de representaciones de la diversidad étnica (no sólo indígena); por ello, no está reconocida en su amplitud, pues solo alude a los pueblos indígenas.

Es importante hacer un análisis de la frase que hemos tomado del artículo $2^{\circ}$ constitucional, ya que, por un lado, se considera que existen los pueblos indígenas como iguales entre ellos, por el denominador común de ser indígenas. Es decir, un término tan general como lo es el de «pueblo indígena», carga con el significado de pluriculturalidad y, a la vez paradójicamente invisibiliza a otros pueblos que no son indígenas, e incluso invisibiliza la riqueza y diversidad de culturas que cada pueblo tiene en su interior. Es decir, la pluriculturalidad en términos sociales y antropológicos no solo se observa entre los polos sino en su interior. De esta manera, en cada uno de los pueblos indígenas de México, existen variantes y formas distintas de «ser», por ejemplo, entre los tseltales o los mixes. Y como se ha señalado, mucho menos se contemplan, en esa oración del artículo $2^{\circ}$, otras 
culturas como las afroamericanas o negras u otras tantas que existen en la República mexicana como los menonitas, los roms o gitanos, o bien, colonias de extranjeros naturalizados.

Lo anterior muestra que finalmente la diversidad cultural se ha centrado en esos dos polos: indígenas y no indígenas, sin considerar otras expresiones culturales, suerte que sigue la educación intercultural que en sus orígenes fue estructurada y aplicada como educación indígena bilingüe -Pérez (2009) la ubica en los años setenta-.

\section{PLURICULTURALIDAD Y MULTICULTURALISMO}

En el contexto arriba planteado podemos decir que las acciones gubernamentales y de política pública, en general, se han quedado, única y exclusivamente, en el reconocimiento de la diversidad cultural y de los derechos, sin que esto realmente cambie la situación de los indígenas frente al resto de la sociedad y mucho menos frente al Estado nacional. A este fenómeno de reconocer lo que existe -es decir, las culturas y la diversidad-, y el ejercicio de derechos sin garantizar la infraestructura, las autoridades y los procedimientos para hacerlo efectivo, es lo que diversos intelectuales críticos han llamado «multiculturalismo» (Valladares 2009).

Tanto el multiculturalismo como la interculturalidad son conceptos asociados al de pluriculturalidad, que suponen la interrelación entre culturas diversas que coexisten en un territorio determinado; más que concebirlas como separadas o ajenas, se considera que es inevitable su relación; el punto es la distinción entre el ser y el deber ser de esa relación, lo que dice la norma y lo que se da de hecho en la realidad: ¿Qué hacemos como sociedad para cumplir? ¿Qué le toca hacer a los indígenas? ¿De qué manera se da o se tiene que dar? ¿Qué factores se deben tomar en cuenta para ello? ¿Qué espacios existen o deben crearse para que se dé esa relación? ¿Qué acciones gubernamentales o políticas públicas deben implantarse? 
En el trabajo mencionado antes (Ortelli et al. 2012) expresamos que los conceptos de multiculturalismo e interculturalidad han sido ampliamente debatidos y cuestionados. Así, la mayoría de los autores de origen anglosajón consultados (Valladares et al. 2009) reconocen que la raíz de estos conceptos es liberal y que se han establecido en el marco de un liberalismo de Estado que pretende simular o encubrir las desigualdades estructurales. Desde esta perspectiva se concibe el multiculturalismo como «un proyecto cultural del neoliberalismo, lo consideramos como una nueva colonización “desde arriba” (Valladares 2009: 193).

De esta manera se puede entender que el multiculturalismo, por un lado, elogia la pluriculturalidad y promueve los derechos y la convivencia ciudadana, derivados de esta diversidad cultural. Por otro lado, y contrario a esto, tenemos la postura que lo critica, ya que el multiculturalismo, aunque promueve reformas legales, no llega a cambiar las estructuras que mantienen la desigualdad entre los ciudadanos que provienen de culturas y pueblos diversos, tal como lo señala Burguete (en dictamen):

\begin{abstract}
Se puede concluir en que a más de treinta años de emergencia indígena en América Latina, en la lucha por territorios, autogobierno y por la descolonización del poder; las respuestas desde el Estado han sido políticas de reconocimiento emitidas en gramática multicultural, que no buscan cuestionar las jerarquías étnicas, sino apenas tratan de encontrar acomodos para los pueblos indígenas, tratándolos como minorías, para que ésos sean funcionales al capital y al orden de cosas existentes.
\end{abstract}

Por otro lado, existen autoras que reconocen los orígenes del multiculturalismo no sólo en los países anglosajones sino también en Latinoamérica, pero con especificidades asociadas con el surgimiento de los movimientos indígenas y con las luchas anticoloniales (Pérez 2009: 251). Esto, a diferencia de la experiencia anglosajona y europea, cuya génesis se da en «una historia conflictiva de resistencia, integración y trasformación, en el seno de las 
luchas por los derechos civiles y los movimientos contraculturales de la década de los años sesenta del siglo pasado» (Zárate 2009: 420). De esta manera, las connotaciones negativas, sobre todo del concepto de multiculturalismo, se vinculan más a las intenciones de los Estados por encubrir las desigualdades y no enfrentar la complejidad de la diversidad, ubicándola como un problema más que como una posibilidad, es decir, se reconoce y elogia la diversidad cultural para incorporar ${ }^{2}$ a los pueblos indígenas a las redes de reproducción del capital, y se trata entonces de una readecuación del sistema de dominación: «En otras palabras, el multiculturalismo es una forma de racismo negada, invertida, autorreferencial, un racismo con distancia, que respeta la identidad del 'otro', concibiendo a éste como una comunidad auténtica cerrada, hacia la cual él -el multiculturalista- mantiene una distancia que se hace posible gracias a su posición universal privilegiada» (Zárate 2009: 444).

Por otro lado, se reconocen que el multiculturalismo como política de estado plantea retos: «si bien responde en alguna medida a las demandas de los pueblos y organizaciones indígenas, tienen grandes retos en relación con replantear las inequidades existentes y resolver la gran brecha existente entre el reconocimiento de derechos y su ejercicio» (Valladares 2009: 193).

De igual forma, si entendemos que la interculturalidad es una fase del multiculturalismo, es decir, se puede concebir como una posibilidad a futuro que dé lugar a nuevos proyectos sociales, entonces: «la interculturalidad actúa como el componente básico para proyectar la convivencia ética y política de las futuras propuestas de sociedad y para esbozar formas alternativas de desarrollo tecnológico y de relacionarse con el medio ambiente natural» (Pérez 2009: 260). Así, por lo que toca a Latinoamérica, el multiculturalismo es una opción ético-política ante la imposición y el fracaso de un modelo de nación sustentado en la homogenización cultural y lingüística (Pérez 2009: 256). 


\section{LOS DERECHOS DE LOS INDÍGENAS Y SUS PUEBLOS Y EL SISTEMA INTERNACIONAL DE DERECHOS HUMANOS}

En la figura 1 (cf. Organización de Naciones Unidas 2012) se puede apreciar el Sistema Internacional de Derechos Humanos (SIDH? (como conjunto de instrumentos jurídicos internacionales, tratados, convenciones, agencias especializadas y organismos).

En la parte de arriba tenemos la Asamblea General, en donde se encuentran varios organismos, entre otros, el Consejo de Derechos Humanos; debajo, el Consejo de Seguridad y el Consejo Económico y Social de Naciones Unidas. Este último nos interesa especialmente porque de él dependen un conjunto de organismos y agencias especializadas en materia de derechos humanos que forman parte del SIDH.

Figura 1. Sistema Internacional de Derechos Humanos. Organismos e Instrumentos Internacionales

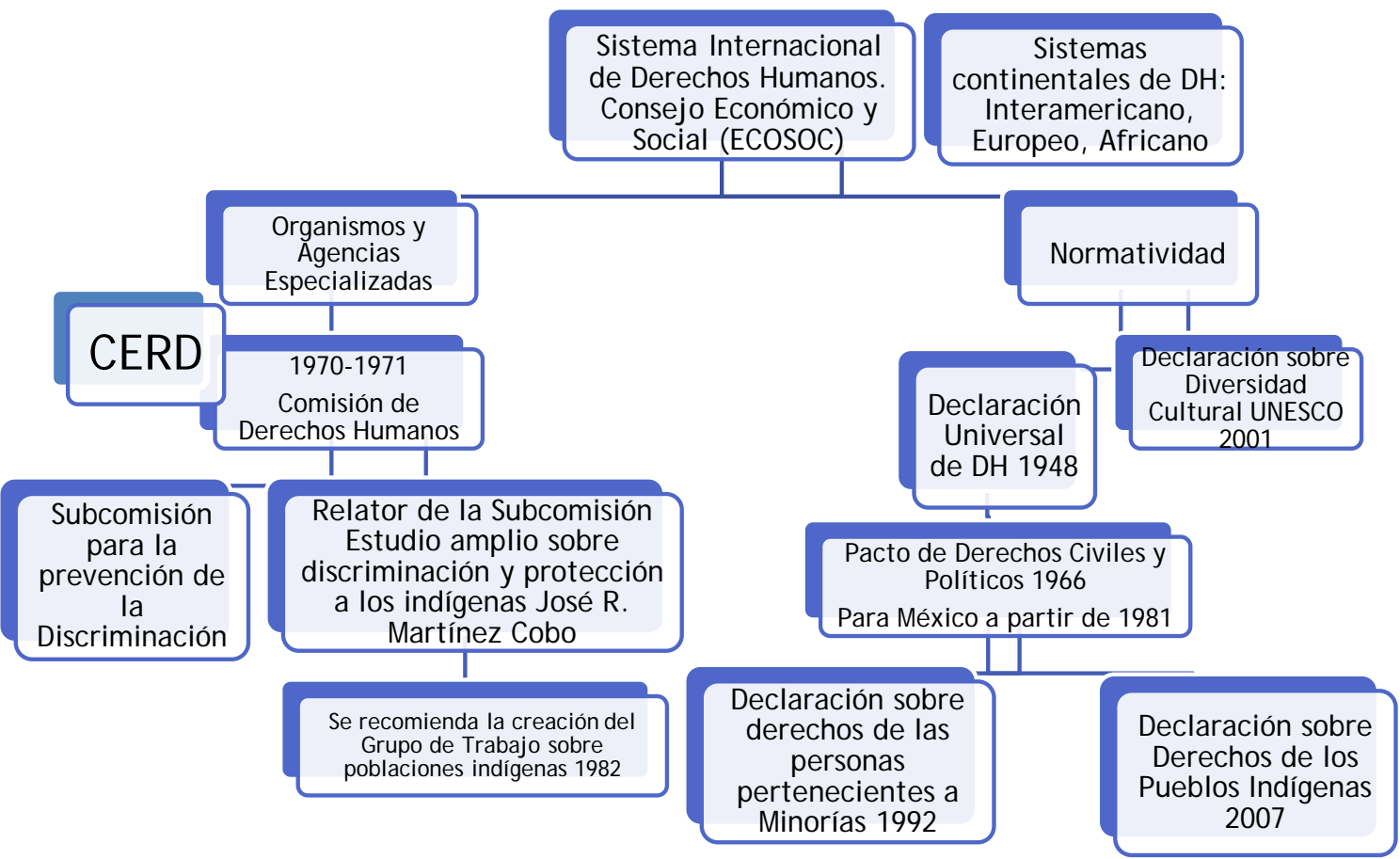

Fuente: Elaboración propia. 
De igual forma, en la figura 1 se puede apreciar que dentro del sistema se encuentran un conjunto de Comités de Derechos Humanos especializados en distintos temas (figura 3). Para el tema que nos ocupa de derechos humanos de indígenas y sus pueblos, está el Comité para la Eliminación de la Discriminación Racial (CERD), del cual derivó en su época el Grupo de Trabajo sobre Poblaciones Indígenas.

Figura 2. Parte orgánica del Sistema Internacional de Derechos Humanos

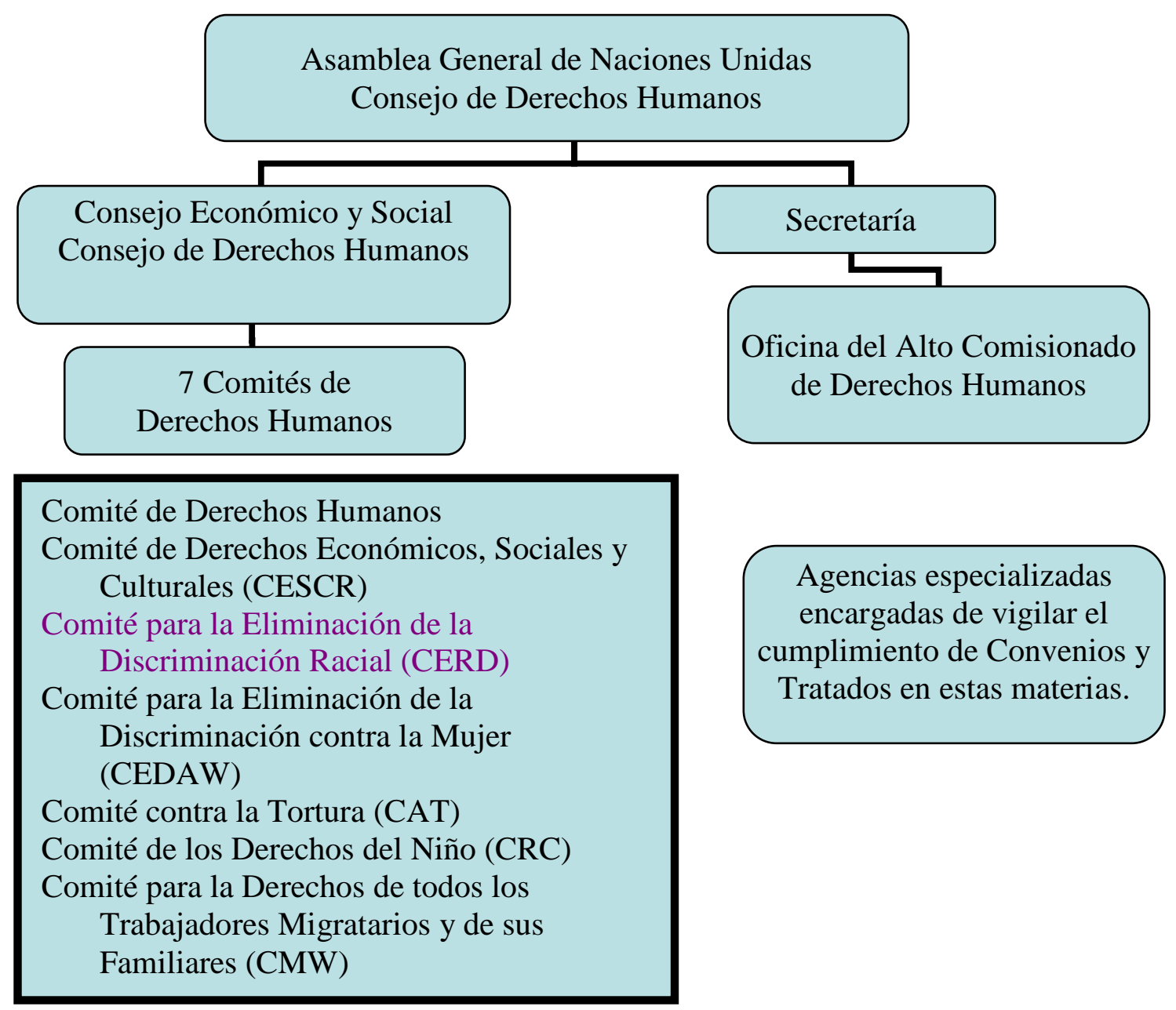

Fuente: Elaboración propia. 
En la figura 2 también se puede apreciar cómo ha sido la evolución de estos derechos desde el establecimiento de la Comisión de Derechos Humanos en 1970, la Subcomisión para la prevención de la Discriminación y la Creación del Grupo de Trabajo sobre poblaciones indígenas en 1982, esto, por lo que toca a la parte orgánica

De lado derecho del organigrama tenemos otros sistemas internacionales de derechos humanos pero de carácter regional: africano y el Interamericano.

En la figura 3, en seguida, se puede observar con más detalle dónde y cómo se sitúa el tema de los derechos indígenas en el Sistema Internacional.

Figura 3. Comités de Derechos Humanos ONU.

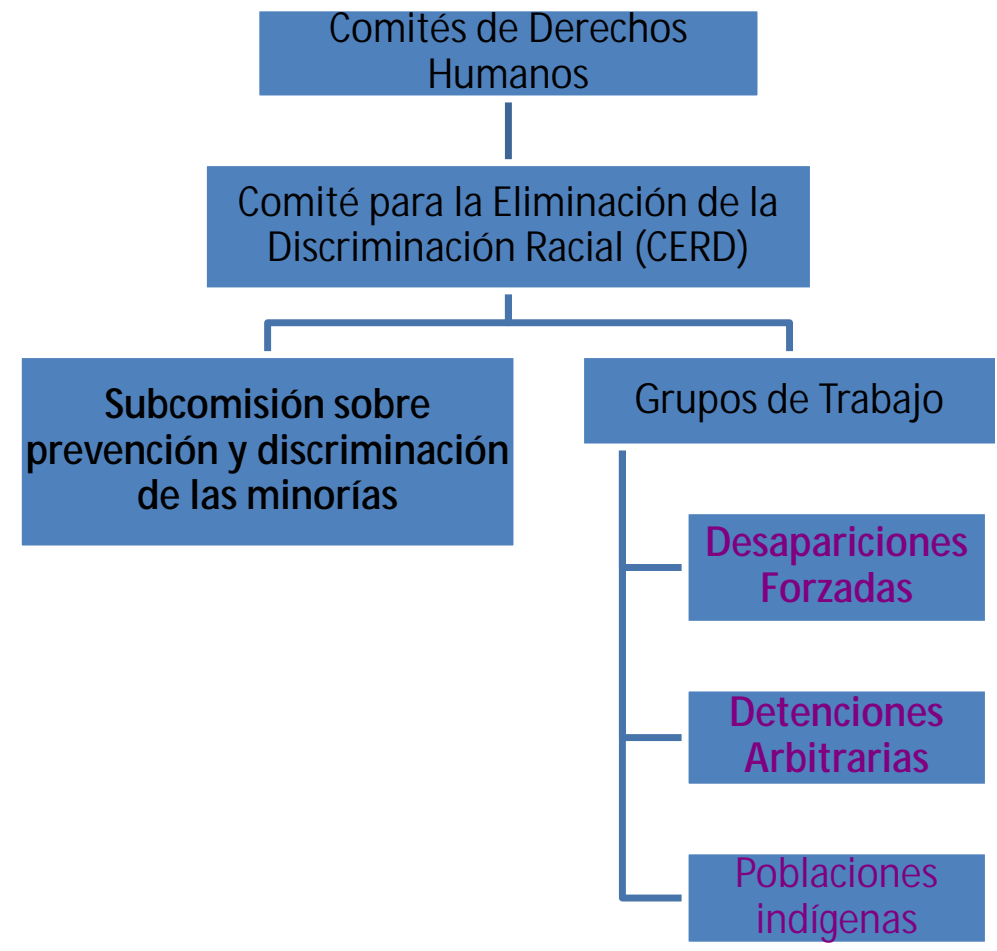

Fuente: Elaboración de Elisa Cruz Rueda 
Por lo que se refiere a la parte normativa, que se ubica por debajo del ECOSOCO, corresponde a los instrumentos jurídicos internacionales existentes sobre Derechos Humanos: declaraciones, protocolos, tratados, convenios, convenciones; que en términos muy breves son los siguientes (Cuadro 1. Cf. Ortelli y Cruz 2011):

Tabla 1. Instrumentos internacionales de derechos humanos.

- Declaración Universal de Derechos Humanos (10/XII/1948).

- Pacto Internacional de Derechos Económicos Sociales y Culturales (1966-3/I/1976).

- Pacto Internacional de Derechos Civiles y Políticos (1966-23/III/1976).

- Protocolos Facultativos de esos Pactos (PIDESC 3/i/1976 el PIDCP desde 1976).

- Declaración sobre el Derecho al Desarrollo ONU (1986).

- Convenio 107 (1957) y 169 de la OIT (1990).

- Declaración Universal de la UNESCO sobre Diversidad Cultural (2001).

- Recomendaciones del Relator Especial sobre la situación de los derechos humanos y las libertades fundamentales de los indígenas (Rodolfo Stavenhagen 23 de diciembre de 2003).

- Declaración Universal sobre Derechos de los Pueblos Indígenas (2007).

- Instrumentos Americanos de Derechos Humanos (OEA).

- Convención Americana de Derechos Humanos.

- Proyecto de Declaración Americana sobre Derechos de los Pueblos Indígenas.

- Comisión Interamericana de Derechos Humanos (Washington).

- Corte Interamericana de Derechos Humanos (Costa Rica).

Fuente: Elaboración propia.

De los cuales nos interesan especialmente los que directamente se refieren a los indígenas y sus pueblos:

- Convenio 169 de la OIT (1990)

- Declaración Universal de la UNESCO sobre Diversidad Cultural (2001)

- Declaración sobre Derechos de los Pueblos Indígenas ONU (2007)

- Artículo $2^{\circ}$ de la Constitución Política de los Estados Unidos Mexicanos (2001)

- Código Federal de Procedimientos Penales (Cámara de Diputados Federal 1991) 
- Recomendaciones del Relator Especial sobre la situación de los derechos humanos y las libertades fundamentales de los indígenas, Sr. Rodolfo Stavenhagen (23 de diciembre de 2003).

Lo anterior es el marco jurídico internacional y nacional que sustenta al peritaje antropológico, y es la base para argumentar su utilidad como una herramienta en el diseño de políticas públicas de y para la diversidad. Antes de explicar esto expliquemos a grandes rasgos las implicaciones en el reconocimiento de la pluriculturalidad y/o la diversidad cultural.

\section{ACCIONES AFIRMATIVAS Y DISCRIMINACIÓN POSITIVA}

Para comprender este apartado y los subsiguientes en los que se detalla el marco jurídico que sustenta al peritaje antropológico, es importante recordar que este surge en los años ochenta en un contexto marcado por el no reconocimiento a la diversidad cultural, ya que los Centros de Readaptación Social (CERESOS) estaban sobrepoblados sobre todo por la presencia de presos indígenas que ni siquiera entendían el español por ser monolingües en su lengua materna. Este es el antecedente de lo que fue el artículo $4^{\circ}$ constitucional, antes de las reformas de 2001, en el que se señalaba, entre otros, el derecho a contar con traductor; posteriormente derivó en la necesidad de contar con un intérprete y con un perito que conociera los usos y las costumbres en materia agraria. Es importante hacer una aclaración fundamental: aunque el derecho a la diversidad está reconocido jurídicamente a nivel nacional e internacional, por lo que respecta al peritaje antropológico como tal, no existe un reconocimiento explícito, ya que la ley nacional, concretamente el Código Federal de Procedimientos Penales, se refiere a las periciales en general. En este punto es crucial tomar como referencia fundamental el marco jurídico expuesto, porque es la base de las responsabilidades y obligaciones que asumen los Estados y los gobiernos para respetar y cumplir con los Derechos Humanos. Los mecanismos y procedimientos (parte de las políticas públicas) que deberán establecer, tendrán que diseñarse y ejecutarse sobre esa 
base. Así, el argumento central que se deriva de esto es que el peritaje antropológico como pericia especializada encaminada al respeto de la diversidad es consustancial para la eficacia de los derechos individuales y colectivos de los indígenas, y para establecer políticas públicas encaminadas al reconocimiento de la diversidad cultural.

El reconocimiento de derechos a las personas por su condición étnica, racial, sexual, religiosa, de género o edad, por ser de naturaleza jurídica, implica la constitución y creación de los instrumentos (p. ej. el peritaje antropológico), las instituciones y autoridades encargadas de cumplir y hacer cumplir esos derechos, como la imposición de las obligaciones tanto para estos como para el resto de los ciudadanos que en nuestro país tenemos que cumplir para el ejercicio eficaz de esos derechos.

En el marco del panorama arriba planteado de manera sumamente breve, se reconocen políticas de Estado en acciones afirmativas y en discriminación positiva (ambas son dos caras de la misma moneda: a un derecho reconocido para el sujeto $A$ corresponden obligaciones para el sujeto $B$-posiblemente traducidas en restricciones, en preferencias y privilegios-), que pretenden eliminar las prácticas discriminatorias en contra de sectores históricamente excluidos como algunos grupos étnicos o con preferencias sexuales distintas. Se privilegia entonces a esos sectores históricamente discriminados en el acceso a recursos y espacios, antes limitados para ellos. Se conciben como medidas temporales y transitorias que permitan pasar a una etapa de igualdad real más que formal, jurídica o discursiva.

\section{EL MARCO JURÍDICO DEL PERITAJE ANTROPOLÓGICO}

En otro trabajo (Cruz 2012) representamos el marco jurídico mexicano con una pirámide, ya que a partir de esta figura podemos entender varios principios constitucionales como el de la supremacía de la Constitución Política de los Estados Unidos Mexicanos (CPEUM). 
Figura 4. Marco jurídico mexicano en materia de Derechos Humanos.

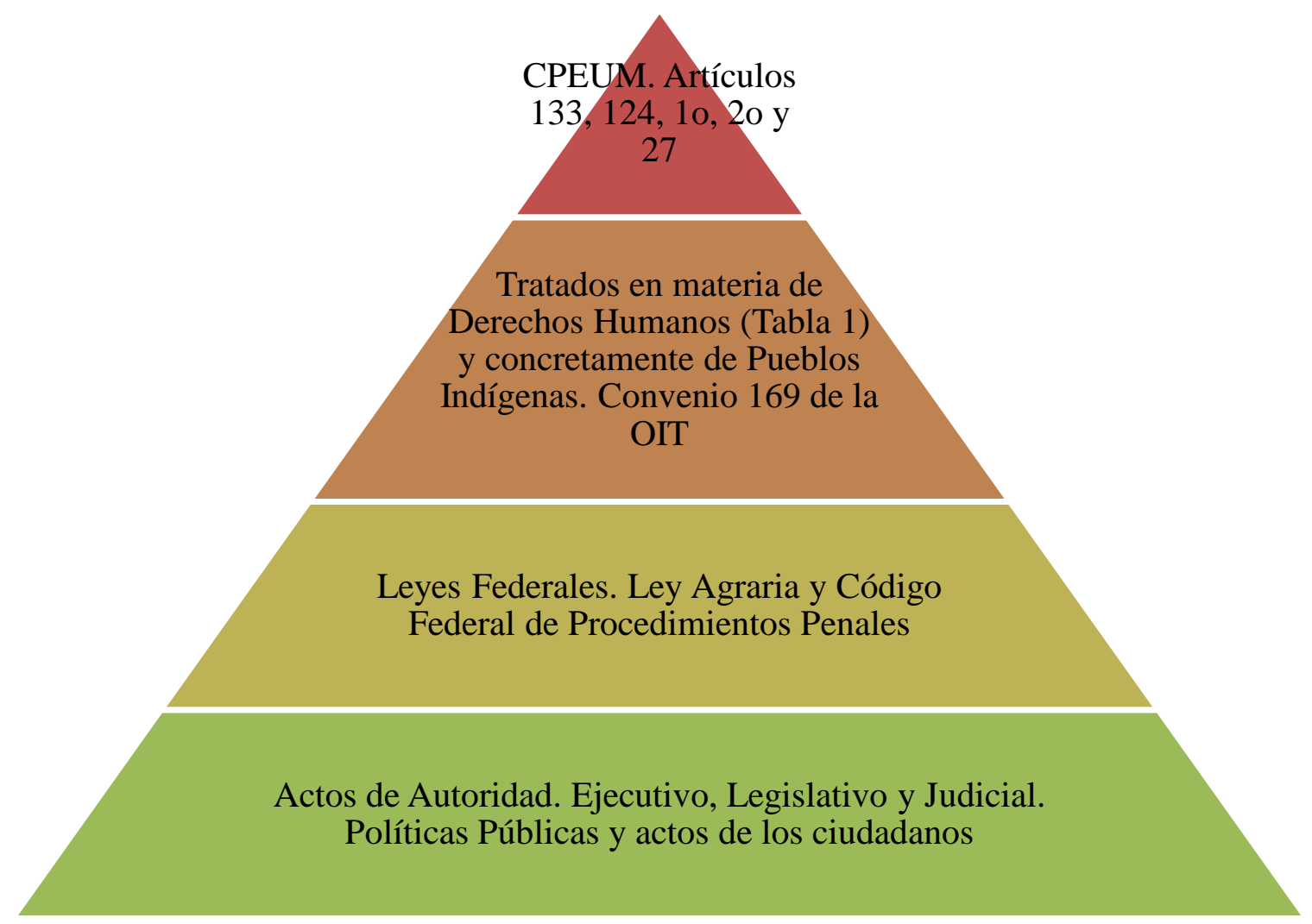

Fuente: Elaboración propia.

Como se puede observar en la parte superior de la pirámide, la CPEUM es la Ley Suprema de toda la Unión de entidades federativas, y las Constituciones locales de cada una de ellas se sujetan a esa Ley Suprema (esto, conforme a los artículos 133 y 124 de la CPEUM).

Artículo 133. Esta Constitución, las leyes del Congreso de la Unión que emanen de ella y todos los Tratados que estén de acuerdo con la misma, celebrados y que se celebren por el Presidente de la República, con aprobación del Senado, serán la Ley Suprema de toda la Unión. Los jueces de cada Estado se arreglarán a dicha Constitución, leyes y tratados, a pesar de las disposiciones en contrario que pueda haber en las Constituciones o leyes de los Estados. 
Artículo 124. Las facultades que no están expresamente concedidas por esta Constitución a los funcionarios federales, se entienden reservadas a los Estados.

La expresión gráfica de la jerarquía de las normas mostrada en la pirámide, así como lo que se deriva de la lectura de los artículos constitucionales, se concretiza en el principio de supremacía constitucional que se resume en la oración: «nada ni nadie por encima de la Constitución». Justamente el artículo 133 de la Constitución Federal nos remite a considerar otros artículos que obligan a la aplicación de los Convenios y Tratados en materia de Derechos Humanos, concretamente nos referimos al artículo $1^{\circ}$ Constitucional que se encuentra en el Capítulo 1 «De los Derechos Humanos y sus garantías», que a la letra señala:

Artículo $1^{\circ}$. En los Estados Unidos Mexicanos todas las personas gozarán de los derechos humanos reconocidos en esta Constitución y en los tratados internacionales sobre derechos humanos de los que el Estado Mexicano sea parte, así como de las garantías para su protección, cuyo ejercicio no podrá restringirse ni suspenderse, salvo en los casos y bajo las condiciones que esta Constitución establece.

Las normas relativas a los derechos humanos se interpretarán de conformidad con esta Constitución y con los tratados internacionales sobre derechos humanos antes señalados.

Todas las autoridades, en el ámbito de sus competencias, tienen la obligación de promover, respetar, proteger y garantizar los derechos humanos de conformidad con los principios de universalidad, interdependencia, indivisibilidad y progresividad. En consecuencia, el Estado deberá prevenir, investigar, sancionar y reparar las violaciones a los derechos humanos, en los términos que establezca la ley.

Finalmente, la intención de abordar los artículos de la Constitución y los instrumentos jurídicos internacionales es mostrar la grave responsabilidad que el Estado y los gobiernos mexicanos tienen, y sobre todo el reto que el Poder Judicial Federal y de los estados para cumplir y hacer cumplir los Derechos Humanos, ya que les obliga a ser expertos en la materia y no solo en el conocimiento del derecho interno (Cf. con Rodríguez 2012: 30). 


\section{CONVENIO 169 DE LA OIT}

El nombre oficial de este instrumento internacional es Convenio 169 de la OIT para Pueblos Indígenas y Tribales en Países Independientes, se considera como el único que se refiere a los pueblos indígenas y que tiene carácter vinculante. En él se establecen los derechos colectivos y derechos individuales de los pueblos indígenas y sus miembros. Además de este instrumento, existen otros que se refieren a los Derechos Humanos en general que no tienen carácter vinculante, pero que integran el Sistema Internacional de Derechos Humanos (véase cuadro 1), y que por el principio de integridad e interdependencia, junto con los derechos que señala el Convenio 169 de la OIT, se aplican a los indígenas y sus pueblos.

Es importante recordar, que este convenio revisa al Convenio 107 de la OIT para Poblaciones Indígenas y Tribales (1957), que es fundamentalmente de corte paternalista y asimilacionista. En este Convenio 107 se partía de la idea de que todas las sociedades humanas estaban en evolución, por lo tanto, las sociedades indígenas, como sociedades primitivas, tenían que desaparecer al momento de lograr el «desarrollo» a la manera de las sociedades modernas de los países industrializados. Por este hecho se habla de Poblaciones y no de pueblos.

A diferencia de esta postura que enarbolaba el Convenio 107, el C. 169 de la OIT se basa en la idea de que los pueblos indígenas son sociedades permanentes, iguales en dignidad y derechos al resto de las culturas representadas por otros pueblos en el orbe. Por la reivindicación que los pueblos indígenas hicieron para reformar el Convenio 107, se cambia el término de Poblaciones por el de Pueblos, con lo que se subraya su carácter histórico y el reconocimiento de la diversidad cultural y étnica y su aportación a la cultura de la Humanidad. Ese reconocimiento implica, además, otorgar una protección a los pueblos indígenas e impulsarlos a que establezcan sus propias prioridades de desarrollo, lo 
que quedó establecido en el Preámbulo del Convenio 169 y en cada una de sus partes, sobre todo la que tiene que ver con Tierra y Territorio.

Es de tomarse en cuenta que por primera vez después de la reforma al artículo $4^{\circ}$ Constitucional, el Convenio tiene su aplicación y concreción a nivel nacional cuando se cita textualmente en los Acuerdos firmados entre el EZLN, el gobierno federal y el estado de Chiapas en San Andrés Larráinzar.

De esta manera el Convenio 169 de la OIT, incluye derechos individuales y colectivos de indígenas y sus pueblos:

- Igualdad (2).

- Derechos Humanos (3).

- Medidas especiales para salvaguardar sus instituciones, bienes, el trabajo, las culturas y el medio ambiente de los pueblos (4).

- Reconocimiento de sus valores y prácticas sociales, culturales y religiosas y espirituales (5).

- Derecho a la consulta (6).

- Derecho a dar su consentimiento previo e informado (6 y 7).

- Derecho consuetudinario, costumbres y tradiciones (8, 9, 10 y 11$)$.

- Acceso a la justicia del Estado y uso de intérpretes (12).

- Tierra y territorios.

De los anteriores derechos nos interesa subrayar aquellos a los que se refieren los artículos $5^{\circ}, 6^{\circ}$ y $7^{\circ}$, porque establecen la obligación del Estado mexicano de tomar en cuenta los derechos de los indígenas y sus pueblos en las acciones de gobierno y de los tres poderes del Estado, concretamente por lo que se refiere a su Cosmovisión e importancia dentro de la tierra y el territorio. De esta manera, el artículo $5^{\circ}$ señala: 
$\mathrm{Al}$ aplicar las disposiciones del presente Convenio:

a) deberán reconocerse y protegerse los valores y prácticas sociales, culturales, religiosos y espirituales propios de dichos pueblos y deberá tomarse debidamente en consideración la índole de los problemas que se les plantean tanto colectiva como individualmente;

b) deberá respetarse la integridad de los valores, prácticas e instituciones de esos pueblos;

c) deberán adoptarse, con la participación y cooperación de los pueblos interesados, medidas encaminadas a allanar las dificultades que experimenten dichos pueblos al afrontar nuevas condiciones de vida y de trabajo.

Por su parte, los artículos $6^{\circ}$ y $7^{\circ}$ se refieren al derecho que los pueblos indígenas tienen a ser consultados cuando las acciones de gobierno y de los tres poderes del Estado los afectan de una u otra manera (sobre este tema y casos específicos cf. Cruz 2008, 2009).

Por lo que toca a la Declaración Universal sobre la Diversidad Cultural de la Organización de Naciones Unidas para la Educación, la Ciencia y la Cultura, UNESCO (2001) y a la Declaración sobre los Derechos de los Pueblos Indígenas, ONU (2007), no tienen carácter vinculante, es decir, no tienen mecanismos ni organismos para la verificación de su cumplimiento, pero que al ser adoptados en el seno de Naciones Unidas, integran lo que se conoce como juscogens, o costumbre jurídica internacional.

Además de lo anterior, la importancia de estos instrumentos como base jurídica del peritaje antropológico es que plantean la necesidad de promover el respeto a las culturas con miras al establecimiento de una verdadera relación intercultural. Como muestra sólo nos referimos a uno de sus artículos. 
Declaración de la UNESCO

Artículo $4^{\circ}$. Derecho a la diversidad cultural, derecho fundamental

Defensa de la diversidad cultural

Respetar los derechos humanos y las libertades fundamentales, en particular los

derechos de las personas que pertenecen a minorías y los de los pueblos autóctonos.

Prohibición de utilizar el derecho a la diversidad cultural para vulnerar los derechos humanos.

\section{MARCO JURÍDICO INTERNO}

Para finalizar con la revisión del marco jurídico que sustenta al peritaje antropológico, tenemos:

- Artículo $2^{\circ}$ de la Constitución Política de los Estados Unidos Mexicanos (Instituto de Investigaciones Jurídicas 2011)

- Código Federal de Procedimientos Penales (Cámara de Diputados Federal 2012).

Respecto a la materia que nos ocupa es importante apuntar sobre el artículo $2^{\circ}$ constitucional:

- La Nación Mexicana es única e indivisible.

- Se subraya la composición pluricultural de la Nación

- Definición de pueblos indígenas que se retoma del artículo $1^{\circ}$ del C. 169 OIT.

- La conciencia de su identidad indígena deberá ser criterio fundamental para determinar a quiénes se aplican las disposiciones sobre pueblos indígenas.

- Definición de comunidades integrantes de un pueblo indígena,

- El derecho de los pueblos indígenas a la libre determinación se ejercerá en un marco constitucional de autonomía que asegure la unidad nacional. 
- El reconocimiento de los pueblos y las comunidades indígenas se hará en las constituciones y leyes de las entidades federativas, las que deberán tomar en cuenta, además de los principios generales establecidos en los párrafos anteriores de este artículo, criterios etnolingüísticos y de asentamiento físico.

Como se puede observar, la mayor parte del contenido del artículo $2^{\circ}$ constitucional se deriva del Convenio 169 de la OIT.

Es importante detenernos en el punto que se refiere a la conciencia de la identidad indígena. Los orígenes del peritaje antropológico se remontan con antelación a la reforma del artículo $4^{\circ}$ de 1992, precisamente a las solicitudes de jueces y ministerios públicos para que un antropólogo certificara si una persona que se decía indígena dentro de un procedimiento judicial o jurisdiccional, lo era o no. Esta práctica se ha ido modificando poco a poco y ha sido producto del diálogo entre juristas y antropólogos.

Si tomamos en cuenta lo que señala el artículo $1^{\circ}$ del Convenio 169 de la OIT y que estaba en el Convenio 107 de 1957, tal solicitud violentaba y violenta los derechos individuales de los indígenas involucrados en cualquier procedimiento judicial.

Podemos decir que el peritaje antropológico es un dictamen que emite un conocedor o experto en la cultura de los «otros», en este caso, de los indígenas. Se convierte en un medio de prueba cuando es solicitado por el juzgador o por una de las partes actoras en un procedimiento judicial, sobre todo de carácter penal -aunque también se ha utilizado en materia agraria por lo que respecta a la paleografía de documentos precoloniales y coloniales, en los cuales los pueblos sustentan la propiedad de sus tierras-.

El Código Federal de Procedimientos Penales no se refiere al peritaje antropológico de manera explícita: 
Artículo 220bis. «Cuando el inculpado pertenezca a un grupo étnico indígena, se procurará allegarse dictámenes periciales, a fin de que el juzgador ahonde en el conocimiento de su personalidad y capte su diferencia cultural respecto a la cultura media nacional.

En los procedimientos en los que intervengan personas que aleguen tener la calidad de indígenas, la misma se acreditará con la sola manifestación de quien la haga. Cuando el juez tenga duda de ella o fuere cuestionada en juicio, se solicitará a las autoridades comunitarias la expedición de la constancia que acredite la pertenencia del individuo a un determinado pueblo o comunidad»

Nuestra propuesta es hablar de peritajes antropológicos, porque justamente el experto en la cultura del «otro» y de entender las conductas de los individuos en un contexto integral, histórico, social y cultural, es precisamente el antropólogo.

Así, el peritaje antropológico es un instrumento por el cual se puede acceder a la comprensión de la lógica que los pueblos indígenas tienen respecto a su visión del mundo ¿Cómo conciben el desarrollo, la tierra, el buen vivir? ¿Qué normas aplican y cómo lo hacen en la resolución de sus asuntos internos y en relación con la tierra? Respuestas que derivan en concepciones, muchas veces distintas a las que tiene la sociedad hegemónica o dominante. La importancia de dialogar con estas culturas desde una postura de reconocimiento de la diversidad cultural está dada por todo lo explicado hasta ahora y concretamente por las Recomendaciones del Relator Especial sobre la situación de los derechos humanos y las libertades fundamentales de los indígenas (Rodolfo Stavenhagen 23 de diciembre de 2003).

83. Deberá igualmente revisarse la justicia agraria en cuanto afecta a los derechos colectivos de las comunidades y pueblos indígenas, tomando en cuenta los usos tradicionales de la tierra y las formas consuetudinarias de solución de conflictos y litigios.

Para entender mejor lo que arriba señalamos como conductas posibles en un pueblo o comunidad indígena, tenemos un caso en el estado de Campeche, ${ }^{3}$ respecto a una conducta 
aparentemente reiterada en las comunidades mayas de la entidad, por la cual hombres mayores de edad establecen una relación de concubinato con mujeres menores de edad. Esto ha derivado en denuncias de la conducta como «violación equiparada», ${ }^{4}$ pero que en su defensa los hombres han argumentado que más bien su incumplimiento ha sido por no dar la dote que se comprometió. Son pocos los casos que se conocen, por lo que hace falta mucho por hacer en términos de estudio antropológico; sin embargo, de la revisión de los expedientes y por el dicho de las autoridades y de los hombres, al parecer el recurso de denunciar penalmente la conducta ha sido más bien para compensar o castigar la falta en que ha incurrido el hombre de incumplir su compromiso con los padres de la menor.

Después de que las autoridades conocen y saben del marco jurídico que promueve los derechos de los indígenas y sus pueblos, así como de los que obligan a fomentar una cultura de la diversidad, frente a ese tipo de conductas se preguntan: ¿Hasta dónde esa conducta es permitida en la comunidad y dentro de la cultura maya? ¿Hasta dónde los padres de la menor efectivamente dan su consentimiento para que se consume el concubinato? ¿Cómo se contemplan los derechos de la menor dentro de la comunidad? ¿Qué le toca a la justicia del Estado hacer y cómo?

En este tipo de casos, y en todos aquellos donde esté implicada una persona indígena, de cuya conducta se tiene dudas si efectivamente corresponde a un patrón cultural, promovemos que las autoridades utilicen y soliciten los peritajes, para garantizar de ese modo la individualización de las penas, ya sea para agravarlas, atenuarlas o, en definitiva, anular el juicio penal porque la conducta corresponde a otra materia.

\section{EL COLEGIO DE ETNÓLOGOS Y ANTROPÓLOGOS SOCIALES, A. C., UNA COMPILACIÓN ACTUAL SOBRE EL PERITAJE ANTROPOLÓGICO}

El Colegio de Etnólogos y Antropólogos Sociales (CEAS), en su Boletín 2012, «El peritaje antropológico en México: Reflexiones teórico metodológicas y experiencias», publicó 
varios artículos dirigidos a la reflexión y el análisis del peritaje antropológico. En el mismo boletín se incluyen varios peritajes y sus usos: mostrar las normas del derecho indígena en el territorio de origen y cómo se reproducen y adecuan en el territorio de migración; exponer el impacto de la violación y la violencia del Ejército mexicano contra una mujer y cómo esto muestra una violencia estructural hacia su pueblo; mostrar los efectos en la población rural desplazada por la ejecución de megaproyectos; y la concepción sobre la territorialidad y sus usos para comprender que el derecho positivo debe aspirar a ser plural aceptando la diversidad de realidades culturales y sociales (véase cuadro 2). Dada la integración de las normas internacionales de Derechos Humanos al marco normativo nacional (por el artículo $1^{\circ}$ constitucional), podemos decir que el actual derecho positivo debe transformarse en un derecho no de la Nación mexicana, sino de los Pueblos y de las Naciones que coexisten en el territorio mexicano (cf. Animal Político 2013. Consulta a Yaquis por Acueducto).

Este número del Boletín queda enmarcado por el conjunto de instrumentos jurídicos, normas y leyes arriba expuestos. De igual manera, tanto las reflexiones como los casos presentados ahí forman parte de un escenario en que la exigencia de y por los derechos cobra más relevancia por las modificaciones a la Constitución Política de los Estados Unidos Mexicanos en 2011, concretamente la que se refiere al artículo $1^{\circ}$, donde se señala el carácter obligatorio y vinculante de los tratados y convenios en materia de derechos humanos, así como de los mecanismos y las declaraciones emitidas dentro del Sistema Internacional de Derechos Humanos. Justamente, los derechos de los indígenas y sus Pueblos forman parte de este Sistema.

De esta manera, tal como se deriva de la lectura de dicho Boletín tanto en su parte analítica (artículos) como en su parte documental (peritajes como medio de prueba para demostrar la diversidad cultural, la violación de derechos y la inviabilidad de una decisión gubernamental), el peritaje antropológico se vuelve una herramienta indispensable no solo para fomentar el diálogo intercultural, como lo menciona Gallart y Valladares (2012 
responsables del número, junto con Ana Hilda Ramírez), sino también como herramienta al alcance de las autoridades para hacer posible lo que se señala en ese artículo $1^{\circ}$ constitucional.

Cuadro 2. Peritajes antropológicos y sus usos.

\begin{tabular}{|c|c|c|c|}
\hline Asunto & $\begin{array}{c}\text { Instancia a la que se } \\
\text { presenta }\end{array}$ & Resumen & $\begin{array}{c}\text { Actores } \\
\text { involucrados }\end{array}$ \\
\hline $\begin{array}{l}\text { 1. } \begin{array}{l}\text { Violación de } \\
\text { una indígena } \\
\text { Me'phaa por } \\
\text { miembros del } \\
\text { Ejército } \\
\text { mexicano }\end{array} \\
\text { Una historia de } \\
\text { agravios y } \\
\text { desagravios: el } \\
\text { Ejército mexicano } \\
\text { Autores: Rosalva } \\
\text { Aída Hernández y } \\
\text { Héctor Ortiz } \\
\text { Elizondo }\end{array}$ & $\begin{array}{l}\text { Presentado ante la } \\
\text { Corte Interamericana } \\
\text { de } \\
\text { Humanos }\end{array}$ & $\begin{array}{l}\text { Barranca Tecuani, municipio de Ayutla } \\
\text { de los libres en el estado de Guerrero, } \\
\text { el } 22 \text { de marzo del } 2002 \text { la Sra. Inés } \\
\text { Fernández Ortega fue violada por un } \\
\text { militar. El } 30 \text { de agosto de } 2010 \text { a } \\
\text { solicitud de la Corte Interamericana de } \\
\text { Derechos Humanos (CIDH) y, a diez } \\
\text { años de la agresión, obligó al Estado } \\
\text { mexicano a ofrecer una disculpa } \\
\text { pública a Inés por los agravios y la } \\
\text { violación de sus derechos humanos } \\
\text { fundamentales, y a reconocer la } \\
\text { violencia estructural como parte de las } \\
\text { responsabilidades del Estado mexicano } \\
\text { en estos hechos }\end{array}$ & $\begin{array}{l}\text { Corte Interamericana } \\
\text { de Derechos } \\
\text { Humanos } \\
\text { Miembros, del } \\
\text { Ejército Mexicano } \\
\text { Centro de Derechos } \\
\text { Humanos de la } \\
\text { Montaña } \\
\text { Tlachinollan, A. C. } \\
\text { Centro por la Justicia } \\
\text { y el Derecho } \\
\text { Internacional (CEJIL) } \\
\text { Organización del } \\
\text { Pueblo Indígena } \\
\text { Me’phaa }\end{array}$ \\
\hline $\begin{array}{l}2 . \quad \text { Sobre la } \\
\text { organización } \\
\text { comunitaria de los } \\
\text { Triquis de la } \\
\text { Candelaria en la } \\
\text { ciudad de México } \\
\text { y el } \\
\text { mantenimiento } \\
\text { del orden } \\
\text { Autor: } \\
\text { Yuri Escalante } \\
\text { Betancourt }\end{array}$ & $\begin{array}{l}\text { Presentado ante el } \\
\text { juez quincuagésimo } \\
\text { del orden }\end{array}$ & $\begin{array}{l}\text { Fue presentado ante el juez } \\
\text { quincuagésimo sexto de lo penal del } \\
\text { D.F, en el } 2011 \text { por un conflicto } \\
\text { ocurrido en el predio conocido como la } \\
\text { Candelaria, localizado en la zona de la } \\
\text { Merced de la ciudad de México. Por } \\
\text { acuerdo de la Mesa Directiva de la } \\
\text { vecindad, lo moradores Triquis } \\
\text { detuvieron a un vecino por los } \\
\text { problemas que ocasionaba en estado de } \\
\text { ebriedad, sin embargo, las autoridades } \\
\text { policiacas acudieron al lugar y } \\
\text { acusaron a los habitantes del predio por } \\
\text { la detención arbitraria de su vecino y } \\
\text { paisano. El peritaje da cuenta de la } \\
\text { reproducción de la identidad y de } \\
\text { algunas formas organizativas que como } \\
\text { indígenas tienen derecho a reproducir } \\
\text { en una ciudad que desde hace décadas } \\
\text { es su lugar de residencia }\end{array}$ & $\begin{array}{l}\text { Pueblos indígenas } \\
\text { Triqui } \\
\text { Representantes de } \\
\text { predios } \\
\text { Instituto Nacional } \\
\text { Indigenista } \\
\text { Mesa directiva de la } \\
\text { Candelaria } \\
\text { Asociación de } \\
\text { artesanos y } \\
\text { comercialización } \\
\text { Emiliano Zapata }\end{array}$ \\
\hline
\end{tabular}




\begin{tabular}{|c|c|c|c|}
\hline Asu & $\begin{array}{c}\text { Instancia a la que se } \\
\text { presenta }\end{array}$ & Resumen & $\begin{array}{c}\text { Actores } \\
\text { involucrados }\end{array}$ \\
\hline $\begin{array}{l}\text { 3. Defensa del } \\
\text { pueblo } \\
\text { Temacapulín, } \\
\text { Jalisco en contra } \\
\text { de la construcción } \\
\text { Presa el Zapotillo, } \\
\text { en el estado de } \\
\text { Jalisco } \\
\text { Autor: Anahí } \\
\text { Copitzy Gomes } \\
\text { Fuentes }\end{array}$ & $\begin{array}{l}\text { Presentado en el } \\
\text { juicio de Amparo del } \\
\text { pueblo Temacapulín }\end{array}$ & $\begin{array}{l}\text { Es presentado con el objetivo de } \\
\text { fortalecer la defensa del pueblo } \\
\text { Temacapulín, Jalisco en contra de la } \\
\text { construcción de la presa el Zapotillo, el } \\
\text { cual fue incorporado como una de las } \\
\text { pruebas periciales en el juicio de } \\
\text { amparo que el pueblo interpuso para } \\
\text { detener la construcción de la presa. El } \\
\text { peritaje muestra los efectos sociales, } \\
\text { económicos, psicológicos y culturales } \\
\text { que tiene la relocalización de personas } \\
\text { con motivo de la construcción de este } \\
\text { tipo de megaproyectos. }\end{array}$ & $\begin{array}{l}\text { Comisión Nacional } \\
\text { del Agua } \\
\text { Tribunal } \\
\text { administrativo de } \\
\text { Jalisco } \\
\text { Gobierno de Jalisco }\end{array}$ \\
\hline $\begin{array}{l}\text { 4. Acusación por } \\
\text { delito ambiental } \\
\text { en la modalidad } \\
\text { de corte, } \\
\text { arranque, tala de } \\
\text { árboles contra un } \\
\text { campesino y un } \\
\text { indígena rarámuri } \\
\text { del estado de } \\
\text { Chihuahua } \\
\text { Autor: Víctor Hugo } \\
\text { Villanueva }\end{array}$ & $\begin{array}{l}\text { Presentado ante el } \\
\text { juez de distrito del } \\
\text { estado de Chihuahua, } \\
\text { presentado en junio } \\
\text { de } 2010\end{array}$ & $\begin{array}{l}\text { Presentado ante el juez de distrito del } \\
\text { estado de Chihuahua, en junio de } 2010 \text {. } \\
\text { Responde a una demanda penal por un } \\
\text { delito ambiental en contra de un } \\
\text { campesino y una indígena raramuri } \\
\text { acusados por el delito de corte, } \\
\text { arranque y tala de algunos árboles. Este } \\
\text { peritaje parte de explicar a la autoridad } \\
\text { la importancia que tiene el territorio } \\
\text { para los implicados en este proceso, no } \\
\text { solamente en términos de uso } \\
\text { tradicional de los recursos de su } \\
\text { entorno, sino también como parte de } \\
\text { los derechos que los pueblos indígenas } \\
\text { tienen en sus territorios }\end{array}$ & $\begin{array}{l}\text { Juzgado VIII de } \\
\text { distrito en el estado } \\
\text { de Chihuahua } \\
\text { CERESO Aquiles } \\
\text { Cerdán }\end{array}$ \\
\hline $\begin{array}{l}\text { 5. Vigencia del } \\
\text { sistema de } \\
\text { impartición de } \\
\text { justicia en el } \\
\text { Nueva Vida, } \\
\text { municipio de } \\
\text { Calakmul, } \\
\text { Campeche, } \\
\text { sustentado en su } \\
\text { reglamento } \\
\text { Interno } \\
\text { Autor: Ana Hilda } \\
\text { Ramírez Contreras }\end{array}$ & $\begin{array}{l}\text { Presentado ante la } \\
\text { Comisión Estatal de } \\
\text { Derechos Humanos } 4 \\
\text { de agosto de } 2009\end{array}$ & $\begin{array}{l}\text { Solicitado por la Comisión Estatal de } \\
\text { Derechos Humanos del estado de } \\
\text { Campeche. El conflicto inicia cuando } \\
\text { Guillermo Mendoza López acusó de } \\
\text { sus expulsión al ayuntamiento de } \\
\text { Calakmul, específicamente al señor } \\
\text { Rosendo Reyes Rueda, agente } \\
\text { municipal del ejido Nueva vida. El } \\
\text { peritaje mostró la importancia en la } \\
\text { construcción de normas que permiten } \\
\text { la convivencia armónica de la } \\
\text { comunidad }\end{array}$ & $\begin{array}{l}\text { Comisión } \\
\text { Destatal de } \\
\text { Derechos Humanos } \\
\text { del estado de } \\
\text { Campeche }\end{array}$ \\
\hline
\end{tabular}

Fuente: Elaboración de María Sánchez Velásquez, a partir de artículos del Boletín Colegio de Etnólogos y Antropólogos Sociales, A.C. (2012). 
Como lo apuntan los distintos autores en el Boletín, el peritaje antropológico es una posibilidad de cambio, pero también se ha constituido como una herramienta que promueve la desigualdad de las culturas (Escalante 2012), cuando se obliga a una de ellas a justificarse en los términos de la cultura hegemónica, más cuando en la práctica de la procuración e impartición de justicia no se reconoce el pluralismo jurídico. Esto es claro en los trabajos de Villanueva y de Escalante. Así, por ejemplo, Yuri Escalante (2012) plantea que son más los cuestionamientos sobre el peritaje antropológico como instrumento para mantener las relaciones desiguales entre las culturas, ya que es muy poco lo que se puede lograr para el diálogo cultural. Al igual que Ana Hilda Ramírez (2012), Escalante cuestiona la redacción del artículo 220bis, ya que no se refiere expresamente al peritaje antropológico, por lo que deja abierta la posibilidad de aplicar cualquier otro tipo de pericia que dé elementos al juzgador para determinar la diferencia cultural con respecto a la media nacional, el psicoanálisis, por ejemplo: «Cuando el inculpado pertenezca a algún grupo étnico indígena, se procurará allegarse dictámenes periciales, a fin de que el juzgador ahonde en el conocimiento de su personalidad y capte su diferencia cultural respecto a la cultura media nacional».

En este sentido, Escalante (2012) profundiza en las implicaciones éticas y disciplinares que un perito antropólogo debe sortear para cumplir esta norma, y concluye que «más bien nos dirigimos a determinar si existen factores culturalmente diferentes en la comisión del delito. O sea que nos limitamos a explorar qué diferencias normativas existen entre la cultura indígena y la nacional, de manera que entendamos la distancia o cercanía entre ambas y no a desentrañar su relación con la quimérica media nacional».

Pese a esto, Escalante (2012) muestra las tensiones por las que transita la disciplina en cuanto al peritaje antropológico se refiere, ya que él ha sido uno de los antropólogos más profusos en cuanto a su elaboración, lo que de alguna manea muestra su confianza esa herramienta para hecer posible si no un cambio estructural a mediano plazo, sí un diálogo 
interdisciplinario en el que intervengan antropólogos y jueces o abogados y, por supuesto, de estos con los peritos nativos o peritos legos de su propia cultura.

Por otro lado, y como lo apunta Valladares (2012), frente al cúmulo de casos que requieren la intervención de los peritos antropólogos, la labor del CEAS se ve muy poco. Sin embargo, a la luz de la lectura de este Boletín podemos decir que el balance es positivo, ya que junto con otras instituciones (INAH, UAM Iztapalapa, CIESAS) ha promovido la práctica, sistematización y enseñanza de lo que es y debe ser el peritaje, sin dejar de lado que hace falta mucho por hacer. La tarea no solo corresponde a los antropólogos sino también a los abogados defensores y en general a los operadores de la justicia.

De esta manera, es posible cumplir y hacer cumplir la norma constitucional a través del peritaje antropológico; por ejemplo, en el ámbito jurisdiccional, el derecho al acceso a la justicia solo es posible cuando el inculpado comprende de qué se le acusa (si es materia penal) en qué consiste el procedimiento y logra hacerse entender para hacer posible su adecuada defensa, y esto se resume en el principio jurídico de «un debido proceso legal». Por ello, cuando hablamos de indígenas y sus pueblos, o de la diversidad cultural en general (que no se reduce al binomio mestizos-indígenas, o indígenas-no indígenas como lo señala Villanueva (2012) en el caso de los menonitas en Chihuahua), es necesaria la intervención de los expertos en el tema, es decir, de los que se dedican a la comprensión de la alteridad o de «los otros», que no son exclusivamente los indígenas, como se podrá apreciar en la sección de casos o sección documental que incluye el Boletín, concretamente el caso de la Presa El Zapotillo que expone Anahí Copitzy y Gómez Fuentes (2012).

De igual forma, tanto Escalante (2012) como Villanueva (2012), cada uno por su lado, hacen una crítica a esta práctica antropológica del peritaje en la materia. Ellos, como todos los demás autores y autoras que escriben en este número del Boletín del CEAS, no muestran solo el estado de la cuestión sino que asumen posturas críticas sobre el quehacer antropológico frente a la justicia estatal, que se expresa justamente en las periciales 
antropológicas, lo que proporciona al lector, instruido o no en esta práctica, varias recomendaciones sobre lo que ha sido y no debe ser el peritaje antropológico (véase la tipología propuesta por Villanueva en este Boletín), sustentado en una reflexión teórica y metodológica y, sobre todo, en la experiencia que han desarrollado los autores en por lo menos los últimos veinte años, marcando su inicio la primera reforma en la materia en el CFPP (Cámara de Diputados Federal 1991) y, los primeros cursos en 1997 y 1998 sobre Antropología Jurídica, implementados por la Coordinación Nacional de Antropología del INAH, para transitar en 2001 a los primeros Cursos sobre Peritaje Antropológico y en 2004 al 1er Diplomado en Peritaje en Ciencias Antropológicas, que se realizan desde entonces hasta la fecha, pasando por la organización de varias Jornadas, Coloquios y Talleres sobre peritaje, realizados en varios estados de la República y en Homenaje póstumo a Augusto Urteaga, según da cuenta Gloria Santos en su artículo, publicado en el mismo Boletín.

Regresando al trabajo de Villanueva (2012), es de destacarse que el autor muestra, a partir del análisis de varios peritajes, unos de autoría propia y otros no, el desarrollo de la pericial no solo como documento descriptivo sino argumentativo. De igual forma, a partir de la lectura de una pericial antropológica desarrolla el marco jurídico internacional y nacional sobre el peritaje mismo y sobre los derechos de los pueblos indígenas, que en breves puntos y preguntas le piden que muestre y demuestre a partir de las dinámicas sociales y culturales. Esto para Villanueva es fundamental, y coincido con él, pues para crear convicción en el juzgador, más allá de exhibir generalidades de la desigualdad y de la diversidad cultural, es necesario mostrarla en el caso concreto.

Desde el principio de la lectura del multicitado Boletín, los lectores tendrán preguntas y sus respuestas sobre lo que ha sido el desarrollo del peritaje antropológico en México, lo que es la prueba pericial y el peritaje y, sobre todo, la especificidad e importancia de lo que es el peritaje antropológico. 
Finalmente, como se puede deducir del cuadro 2, el peritaje, en todos los casos, ha servido como herramienta argumentativa en la exigencia de la visibilización y el respeto de los derechos indígenas y sus pueblos (individuales y colectivos). Es decir, ya no solo se utiliza para que el indígena como individuo tenga acceso a información y adecuada defensa en su idioma, cuando está sujeto a un proceso penal, o para demostrar que en su actuar concurrieron distintas condiciones culturales (convicción de que su conducta se apega a sus prácticas y saberes comunitarios), que le permitan el acceso a una justicia culturalmente adecuada. Además, el peritaje antropológico sirve como herramienta argumentativa de cómo se ha dado la relación entre el Estado y la sociedad con los indígenas y sus pueblos, para comprender la profundidad de sus exigencias en el respeto a sus derechos a la tierra y al territorio, a su cosmovisión y cultura en general, entre otros derechos. Es precisamente en esta característica del peritaje antropológico en el que sustentamos nuestra propuesta de usarlo como una herramienta para el diseño de políticas públicas para la diversidad.

Con la lectura de los trabajos de distintos autores puedo señalar que la mayor aportación de este número del Boletín no es dar una postura complaciente o autocomplaciente de lo que ha sido el peritaje antropológico en México, sino más bien generar el debate a partir de distintas posturas críticas y sin afán de idealizar el instrumento.

\section{CONCLUSIÓN}

De lo expuesto hasta aquí solo queda apuntar algunas ideas que resumen finalmente la importancia del peritaje antropológico y su uso para lograr una justicia culturalmente adecuada y, sobre todo, el diseño y la implantación de políticas públicas (acción e inacción) de gobierno y de Estado que tengan como eje central la visibilización y el respeto de la diversidad en general y de la diversidad cultural. 
¿QUÉ ES O DEBIERA SER EL PERITAJE ANTROPOLÓGICO?

- Herramienta que contribuye a la inclusión de la diferencia cultural en la norma jurídica y en su aplicación: diseño de políticas públicas y decisiones de gobierno y de Estado, así como en la procuración e impartición de justicia dirigida a los indígenas y sus pueblos.

- No es sólo un medio de prueba dentro de un proceso judicial, sino que es un instrumento para comprender la existencia de pueblos con culturas diferentes.

- Es importante para lograr el entendimiento entre lógicas jurídicas, sociales y culturales distintas.

- Debe volverse un instrumento eficaz para la construcción de una nueva relación entre el Estado y la sociedad, y concretamente entre las instancias de gobierno y sus dependencias con los indígenas y sus pueblos.

- Es un medio de prueba, pero también es un instrumento argumentativo por el cual se puede acceder a la comprensión de la lógica que los pueblos indígenas tienen en la resolución de sus asuntos internos y en relación con la tierra, que muchas veces es distinta a la de la sociedad hegemónica o dominante.

Los ejemplos abordados en el Boletín del CEAS muestran que el peritaje antropológico o cultural permite de una manera rápida y clara dar cuenta de la necesidad de reorientar y redefinir la política de Estado respecto de los pueblos indígenas, concretamente en cuanto a:

- Las políticas públicas (decisiones, acciones e inacciones del gobierno cuya expresión son los programas sociales y proyectos extractivos y de infraestructura en territorios indígenas),

- Los procesos jurisdiccionales en los que están implicados indígenas y sus pueblos,

- Los instrumentos y procedimientos legales en cualquier materia en la que estén involucrados indígenas y sus pueblos (o se violenten sus intereses culturales) y, 
- Los cambios constitucionales y legales.

Cualquiera de los cuatro puntos señalados debe pasar por un proceso de consulta (Cruz 2009), respetando los principios de buena fe, de adecuación de los mecanismos que se adopten para ese fin a las formas propias en las que los pueblos indígenas toman sus decisiones. Por ejemplo, para aprender y aprehender esto, es útil y necesario el peritaje antropológico, que, hecho por el experto en la cultura de los «otros» ${ }^{5}$, mostrará esas formas de toma de decisiones y de ejercicio de la libre determinación al interior de los pueblos y comunidades indígenas, así como los valores culturales que se trastocan por políticas públicas que no consideran ni respetan los derechos humanos (individuales y colectivos) de indígenas y sus pueblos.

\section{FUENTES DE CONSULTA}

Animal político, 2013, «Aprueba la Corte petición de yaquis sobre acueducto» en http://www.animalpolitico.com/2013/08/aprueba-la-corte-peticion-de-yaquis-sobreacueducto/\#ixzz2bVyot1FU [consulta: 9 de agosto de 2013].

Burguete Cal y Mayor, Araceli (en dictamen), «Multiculturalismo constitucional en Chiapas: reformas huecas para nulificar derechos autonómicos», en Latin America's Multicultural Movements and the Struggle between Communitarianism, Autonomy, and Human Rights, editado por Todd Eisenstadt.

Cámara de Diputados Federal, 1991, Código de Federal de Procedimientos Penales, en http://www.diputados.gob.mx/LeyesBiblio/ref/cfpp/CFPP_ref18_08ene91_ima.pdf [consulta: 3 de octubre de 2013].

Cámara de Diputados Federal, 2012, Código de Federal de Procedimientos Penales, en http://www.diputados.gob.mx/LeyesBiblio/ref/cfpp/CFPP_ref18_08ene91_ima.pdf [consulta: 3 de octubre de 2013]. 
Cámara de Diputados del Estado de Campeche, 2002, «Código Penal del Estado de Campeche», en http://www.colpos.mx/web11/images/meg/Montecillo/Nor/cpc.pdf [consulta: 25 de febrero de 2013].

Colegio de Etnólogos y Antropólogos Sociales (CEAS), 2012, Peritaje antropológico en México: Reflexiones teórico metodológicas y experiencias, CEAS, México.

Cruz Rueda, Elisa, 2008, «Mecanismos de consulta a los pueblos indígenas en el marco del Convenio 169 de la OIT: el caso mexicano», Revista Pueblos y Fronteras Digital, n. 5, Proimmse-IIA-UNAM, México, en http://www.pueblosyfronteras.unam.mx/ index_n5.html [consulta: 20 de mayo de 2012].

2009, «Mecanismos de consulta a los pueblos indígenas en el marco del Convenio 169 de la OIT (versión ampliada)», en Consulta Previa. Experiencias de Aprendizaje. Coordinado por Sánchez Botero, Esther, Instituto Colombiano de Antropología e Historia y Agencia Nacional de Hidrocarburos, Bogotá, pp. 141-162.

2011, «Eólicos e inversión privada: El caso de San Mateo del Mar, en el Istmo de Tehuantepec Oaxaca», The Journal of Latin American and Caribbean Anthropology, v. 16, n. 2, pp. 257-277.

2012, «Derechos Humanos y Derecho: El Marco Jurídico del Desarrollo», en Debates contemporáneos del desarrollo y miradas desde el sureste mexicano, coordinado por Fletes Ocón, Héctor Bernabé, et al., UACH, San Cristóbal de Las Casas, pp. 97125.

2013, «Derecho a la tierra y el territorio: demandas indígenas, Estado y capital en el Istmo de Tehuantepec», en Justicia indígena y estado. Violencias contemporáneas, editado por María Teresa Sierra, Rosalva Aida Hernández y Rache Sieder, FLACSO, CIESAS, México, pp. 341-382.

Escalante Betancourt, Yuri, 2012, «Ética y verdad. La antropología frente al positivismo jurídico», en Peritaje antropológico en México: Reflexiones teórico metodológicas y experiencias, Boletín del Colegio de Etnólogos y Antropólogos Sociales, México, pp. 33-42. 
Gallart Nocetti, Maria Antonieta y Laura R. Valladares de la Cruz, 2012, «Presentación», en Peritaje antropológico en México: Reflexiones teórico metodológicas y experiencias, Boletín del Colegio de Etnólogos y Antropólogos Sociales, México, pp. 5-10.

Gobierno del Estado de Chiapas, 2012, «Monitor ODM Chiapas. Sistema Integral de Indicadores», en http://planeacionsectorial.chiapas.gob.mx/odm/?page_id=17 [consulta: 20 de mayo de 2012].

Gómez Fuentes, Anahí Copitzy, 2012, «Asunto: Defensa del pueblo Temacapulín, Jalisco en contra de la construcción de la Presa El Zapotillo, en el estado de Jalisco. Presentado en el Juicio de Amparo del pueblo Temacapulín», en Peritaje antropológico en México: Reflexiones teórico metodológicas y experiencias, Boletín del Colegio de Etnólogos y Antropólogos Sociales, México, pp. 87-100.

Instituto de Investigaciones Jurídicas, Universidad Autónoma de México, 1984, Diccionario Jurídico Mexicano, Tomo VIII, 1a. Edición, México, en http://www.bibliojuridica.org/libros/libro.htm?l=1174 [consulta: 25 de febrero de 2013].

Instituto de Investigaciones Jurídicas, Universidad Autónoma de México, 2011, «Constitución Política de los Estados Unidos Mexicanos», en http://info4.juridicas.unam.mx/ijure/fed/9/ [consulta: 6 de mayo de 2011].

Organización de Naciones Unidas (ONU), 2007, «Declaración sobre los Derechos de los Pueblos Indígenas», en http://daccess-ddsny.un.org/doc/UNDOC/GEN/N06/512/10/PDF/N0651210.pdf?OpenElement [consulta 3 de octubre de 2013].

Organización de Naciones Unidas (ONU), 2012, «Estructura y organización», en http://www.un.org/es/aboutun/structure/org_chart.shtml [consulta: 20 de mayo de 2012].

Organización de Naciones Unidas para la Educación, la Ciencia y la Cultura (UNESCO), 2001, «Declaración Universal sobre la Diversidad Cultural», en 
http://unesdoc.unesco.org/images/0012/001271/127160m.pdf $\quad$ [consulta: 3 de octubre de 2013].

Ortelli, Paola y Elisa Cruz Rueda, 2011, «La gestión y el autodesarrollo como derechos humanos fundamentales de los Pueblos Indígenas», Revista Pueblos y Fronteras Digital, v. 6, n. 11, Proimmse-IIA-UnAM, México, pp. 246-272, en http:// http://www.pueblosyfronteras.unam.mx/a11n11/art_08.html [consulta: 20 de mayo de 2012].

Ortelli, Paola, Elisa Cruz Rueda y Eliseo Rodríguez Ortiz, 2012, «Negociación y conflicto en la pedagogía intercultural de la gestión y el autodesarrollo indígena», compilado por Fletes Ocón, Héctor Bernabé, et al., Debates sobre el Desarrollo, Licenciatura en Gestión y Autodesarrollo Indígena, Universidad Autónoma de Chiapas, San Cristóbal de Las Casas, pp. 179-205.

Pérez Ruiz, Maya Lorena, 2009, «¿De qué hablamos cuando nos referimos a lo intercultural?», en Estados plurales. Los retos de la diversidad y la diferencia, coordinado por Valladares de la Cruz, Laura, Maya Lorena Pérez Ruiz y Margarita Zárate Vidal, UAM-I, Juan Pablos, México, pp. 251-288.

Ramírez Contreras, Ana Hilda, 2012, «Justicia, peritaje antropológico y normatividad», en Peritaje antropológico en México: Reflexiones teórico metodológicas y experiencias, Boletín del Colegio de Etnólogos y Antropólogos Sociales, México, pp. 21-32.

Red Mexicana de Afectados por la Minería, 2013, «Noticias», en http://rema.codigosur.net/ [consulta: 30 de julio de 2013].

Rodríguez Rodríguez, Magally, 2012, «Proteger derechos de los pueblos indígenas, prioridad del Poder Judicial de la Federación», en Compromiso: Órgano informativo del Poder Judicial de la Federación, año XI, n. 134, Poder Judicial de la Federación, Suprema Corte de Justicia de la Nación, México, pp. 28-30.

Valladares de la Cruz, Laura, 2009, «Colonizando el multiculturalismo. Resistencia y adaptación entre los pueblos indios en tiempos multiculturales», en Estados plurales. Los retos de la diversidad y la diferencia, coordinado por Valladares de la 
Cruz, Laura, Maya Lorena Pérez Ruiz y Margarita Zárate, UAM-I, Juan Pablos, México, pp. 181-226.

2012, «La importancia del peritaje cultural: avances, retos y acciones del Colegio de Etnólogos y Antropólogos Sociales A. C. (CEAS) para la certificación de peritos», en Peritaje antropológico en México: Reflexiones teórico metodológicas y experiencias, Boletín del Colegio de Etnólogos y Antropólogos Sociales, México, pp. 11-20.

Valladares de la Cruz, Laura, Maya Lorena Pérez Ruiz y Margarita Zárate (coords.), 2009, Estados plurales. Los retos de la diversidad y la diferencia, UAM-I, Juan Pablos, México.

Villanueva Gutiérrez, Victo Hugo, 2012, «Crítica al ejercicio del peritaje antropológico en Chihuahua ¿Afirmación o negación del pluralismo jurídico en nuestras peritaciones?», en Peritaje antropológico en México: Reflexiones teórico metodológicas y experiencias, Boletín del Colegio de Etnólogos y Antropólogos Sociales, México, pp. 43-56.

Wikipedia, 2012, «Ejército Zapatista de Liberación Nacional», en http://es.wikipedia.org/ wiki/Ej\%C3\%A9rcito_Zapatista_de_Liberaci\%C3\%B3n_Nacional [consulta: 20 de mayo de 2012].

Zárate Vidal, Margarita, 2009, «Las paradojas de la cultura, la razón de la diversidad o la diversidad de razones: multiculturalismo e interculturalismo», en Estados plurales. Los retos de la diversidad y la diferencia, coordinado por Valladares de la Cruz, Laura, Maya Lorena Pérez Ruiz y Margarita Zárate Vidal, UAM-I, Juan Pablos, México, pp. 413-471.

\section{NOTAS}

\footnotetext{
${ }^{1}$ La iniciativa de reforma como la reforma misma fue muy cuestionada por los representantes del Ejercito Zapatista de Liberación Nacional (EZLN) y sus simpatizantes porque no recogía la propuesta íntegra de la Comisión de Concordia y Pacificación (COCOPA), además de que violentaba los acuerdos firmados con anterioridad y que se referían a las normas de procedimiento de diálogo y negociación entre las partes,
} 
fundamentalmente los llamados diálogos de San Miguel. Para comprender el proceso de diálogo es importante considerar que después del levantamiento del EZLN, el gobierno federal y del estado de Chiapas tuvieron varios acercamientos que se dieron en varias etapas: $1^{\circ}$ Los diálogos de la Catedral, $2^{\circ}$ Los diálogos de San Miguel y $3^{\circ}$ Los Diálogos de San Andrés. Sobre las normas de procedimiento verificar en el documento «Protocolo de Bases para el Diálogo y Negociación del Acuerdo de Concordia y Pacificación con Justicia y Dignidad», como punto de partida del diálogo en San Andrés (cf. Wikipedia 2012).

${ }^{2}$ Considero que este es el término más adecuado y no el de asimilación, porque el sentido de este era el de conseguir un desarrollo general de la nación a costa de borrar las diferencias culturales, es decir, que los indígenas dejaran de «ser» para convertirse en mexicanos y con ello, la nación mexicana lograr el progreso. El término de incorporación se refiere a resaltar las diferencias que pueden tolerarse: el uso de la lengua, el vestuario, la música la historia y tradición oral, pero socavando las diferencias de fondo que cuestionan la estructura del Estado moderno como el ejercicio de gobierno, la autonomía, el derecho indígena y el control territorial.

${ }^{3}$ Desde 2011 la autora Elisa Cruz Rueda participa con la organización Diálogo y Movimiento A. C., en el proyecto piloto de excarcelación de mujeres y hombres indígenas en el estado de Campeche, coordinado por la doctora Artemia Fabre Zarandona. Por ello, ha tenido oportunidad de conocer la postura y visión tanto de los indígenas como de las autoridades de procuración e impartición de justicia.

${ }^{4}$ En el Diccionario Jurídico Mexicano del Instituto de Investigaciones Jurídicas de la UNAM (1984) se señala que la violación es un acto que se ejerce contra una mujer con la intención de imponer la cópula sin consentimiento, por medios violentos. Se denomina violación equiparada cuando la conducta violenta tiene distintas variaciones por la persona que la ejerce y la persona que la recibe, por el tiempo durante el cual se ejerce y la intencionalidad, esto de acuerdo con el artículo 228 del Código Penal del Estado de Campeche (Cámara de Diputados del Estado de Campeche 2002): «Si el pasivo fuese persona menor de doce años de edad o persona que no tenga la capacidad de comprender el significado del hecho o que por cualquiera causa no pueda resistirlo, se aplicará prisión de uno a cinco años y multa de cuarenta a doscientas veces el salario mínimo. Si se hiciere uso de la violencia física o moral el mínimo y el máximo de las penas se aumentarán hasta en una mitad. Cuando el agente ejerciere autoridad sobre el pasivo o fuere su tutor o maestro, o cometiere el delito valiéndose de un cargo o empleo público, o ejerza una profesión y utilice los medios o circunstancias que ella le proporcione, o sea ministro de algún culto, se duplicarán las penas señaladas en los párrafos anteriores».

${ }^{5}$ Es deseable que cada vez haya más antropólogos indígenas que puedan ejercer este peritaje antropológico para evitar una postura de cierto poder, desde los no indígenas. Sin embargo, es importante advertir que estos antropólogos indígenas también tendrían que ser sensibilizados y formados en los conceptos de diversidad y pluralidad cultural, ya que al igual que en otras profesiones (como el derecho) la formación que reciben indígenas y no indígenas en cualquier nivel se ha cuestionado por ser hegemónica y no considerar la pluralidad y diversidad de pensamientos.

\section{Fecha de recepción: 1 de marzo de 2013.}

\section{Fecha de aceptación: 12 de agosto de 2013.}

